

\title{
Self-Repairing Technique Based on Microcapsules for Cementitious Composites- A Review
}

\author{
Zainab H. Mahdi * \\ Assistant Professor \\ Middle Technical University \\ Baghdad, Iraq \\ zainabengineeringcollege@yahoo.com
}

\author{
Asraa Y. Al Goody \\ Lecturer \\ University of Technology \\ Baghdad, Iraq \\ Israa.Y.Algoody@uotechnology.edu.iq
}

\author{
Tabarek J. Qasim \\ B.Sc. student \\ Middle Technical University \\ Baghdad, Iraq \\ Eng.tabarek98@gmail.com
}

\begin{abstract}
Self-repairing technology based on micro-capsules is an efficient solution for repairing cracked cementitious composites. Self-repairing based on microcapsules begins with the occurrence of cracks and develops by releasing self-repairing factors in the cracks located in concrete. Based on previous comprehensive studies, this paper provides an overview of various repairing factors and investigative methodologies. There has recently been a lack of consensus on the most efficient criteria for assessing self-repairing based on microcapsules and the smart solutions for improving capsule survival ratios during mixing. The most commonly utilized self-repairing efficiency assessment indicators are mechanical resistance and durability. On the other hand, Nondestructive methods have been widely used to visualize and assess cementitious composites, self-repairing behavior. However, certain issues remain, such as crack spread behavior, repairing agent kinetics on discrete crack surfaces, and the influence of inserted capsules on the mechanical characteristics of self-repaired cementitious composites, all of which require more investigations.
\end{abstract}

Keywords: Self-repairing, Micro-capsules, Repairing factors, Investigative methodologies, Nondestructive methods.

\footnotetext{
*Corresponding author

Peer review under the responsibility of University of Baghdad.

https://doi.org/10.31026/j.eng.2022.02.05

2520-3339 (C) 2022 University of Baghdad. Production and hosting by Journal of Engineering.

This is an open access article under the CC BY4 license http://creativecommons.org/licenses/by/4.0/).

Article received: 1 / $11 / 2021$
}

Article accepted: 5/ 12/2021

Article published:1/2/2022 


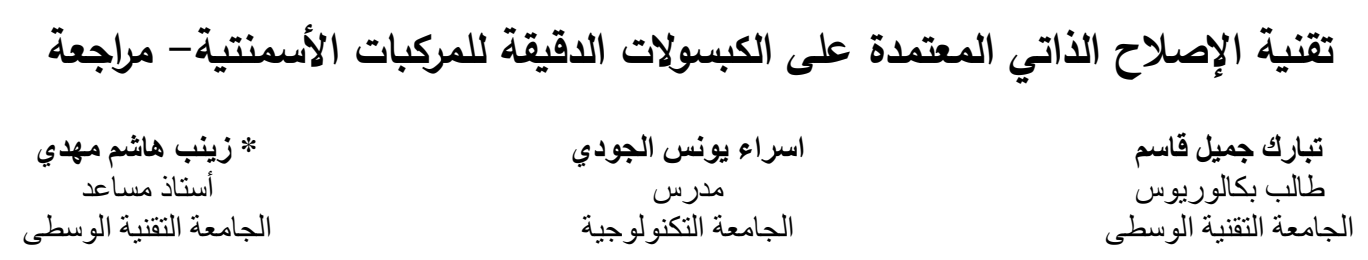

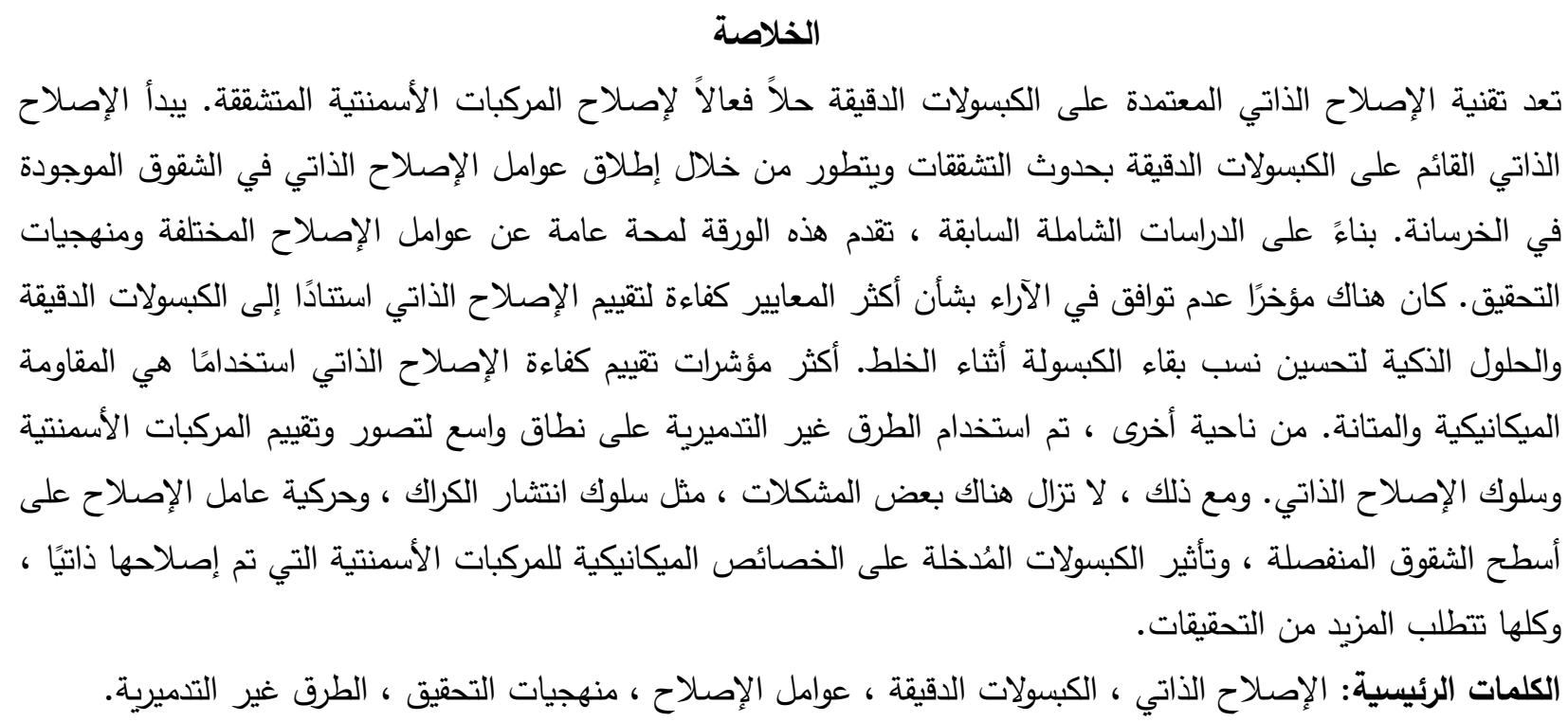

\section{INTRODUCTION}

The most important and widely used building material is concrete due to its excellent serviceability, raw material availability, and compressive resistance (Mehta, 1986). Micro-cracks, on the other hand, can significantly compromise the mechanical resistance and durability of concrete elements (Muhammad, et al., 2016). Water and chloride infiltration through cracks has a significant impact on the durability of concrete elements and causes erosion of steel-reinforcement bars, which leads to failure concerns (Milla, et al., 2021). As a result, it is critical to repair or heal these fractures to keep concrete elements functional (Yıldırım, et al., 2015). Because most of these healing procedures are limited by accessibility, expense, location, and environmental issues, cracks can only be fixed manually in rare cases. (Vijay, et al., 2017). As a result, self-repairing of cracks has become a need for concrete elements, attracting increasing scientific interest. The autogenously healing phenomenon, on the other hand, was seen in nature for many decades (Jacobsen and Sellevold, 1996), (Bekas, et al., 2016). The autogenous is achieved through the production of $\mathrm{CO} 2$ and the continual hydration of anhydrite cement pozzolana binding materials (Jacobsen and Sellevold, 1996), (Huang, et al., 2013) when CO2 and water are available (Cowie and Glasser, 1992). Nevertheless, without additional amendment or enhancement, the efficacy of such repairing actions is rather weak. As a result, different techniques have been developed to increase the behavior of self-repairing (De Belie, et al., 2018), generally by incorporating types of additions like crystalline (Ferrara et al., 2014), (Ferrara, et al., 2016), (Roig, et al., 2015), (Roig, et al., 2016) or mineral admixture (Van, et al. 2012), (Huang, et al., 2014), polymers (White, et 
al., 2001), (Dry, 1994), microencapsulation (Zemskov, et al., 2011), (Van, et al., 2011), (Lv, et al., 2013), (Isaacs, et al., 2013) (Gilabert, et al., 2015), (Van, et al., 2015), hollow fiber (Dry, 1994), microorganisms (Khaliq and Ehsan, 2016), and nanoparticles (Perez, et al., 2015) into cementitious materials. Furthermore, Strain Hardening Cement-based Composites (SHCC) with distinctive micro-crack behavior and narrow crack width control characteristics has a lot of potential for crack self-repairing (Zhang, et al., 2014), (Cuenca and Ferrara, 2017). According to Muhammad et alassessment.'s (Muhammad, et al., 2016) of all existing self-repairing concrete methods, self-repairing based on microcapsules concrete is may the most successful. In addition, when compared to other traditional techniques, the microcapsules strategy's healing process is more flexible, requiring no extra water, having a shorter curing time, and having repeatable sealhealing activities (Thao, et al., 2009), (Van, et al., 2015), (Van, et al., 2016). Self-repairing which is based on micro-capsules for cement pozzolana binding materials was discovered from the investigation presented by White \& co-worker (White, et al., 2001). They suggested a type of crack-self-repairing element with integrated microencapsulation. When this type of microencapsulation is disrupted by crack incursion, it releases a repairing agent that polymerizes with the embedded catalyst to repair and seal the cracks, as seen in Figure 1. Following that, selfrepairing based on microcapsules technology for cementitious materials was widely adopted, and it is now widely acknowledged as the most promising method for concrete infrastructure selfhealing. Figure 2 depicts a typical arrangement of self-repairing based on microcapsules concrete samples. These capsules are positioned perpendicular to the pre-crack in the test, and they're generally close together with other capsules containing water or accelerator to see how additives affect the self-healing process (Feiteira, et al., 2016).

(a)

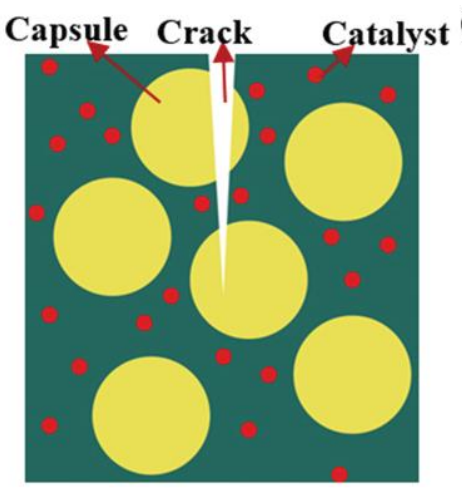

(b)

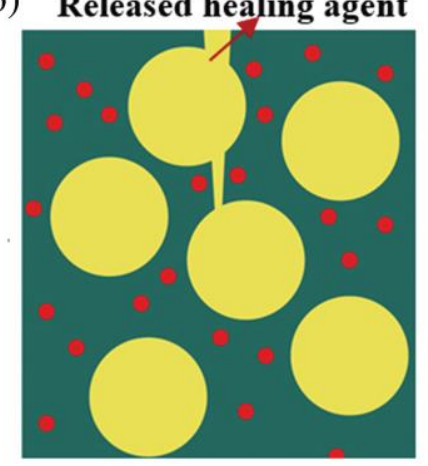

(c)

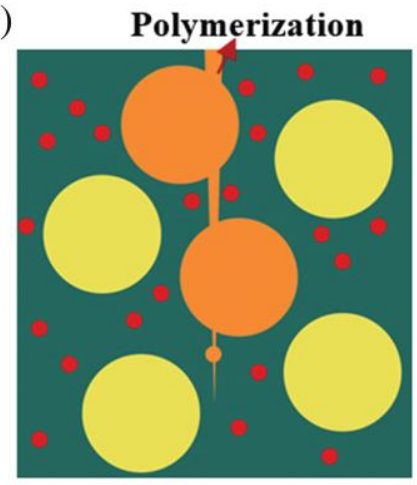

Figure 1. Self-repairing simplified notion for cementitious materials: (a) crack formation, (b) repairing factors spreading; (c) polymerisation (De Belie, et al., 2018).

The capsules' shells are generally made of brittle materials, and concrete samples could be prismatic, cylindrical, based on the experiment's parameters and techniques used. The quick rupturing of previously placed capsules, the penetration of repairing factors into the crack area, and the subsequent sufficient cure responses are critical to the repairing concept of self-repairing 
based on microcapsules concrete (Gilabert, et al., 2017). As a result, these three subprocesses must be triggered as soon as possible to ensure high-efficiency self-repairing (Kessler, et al. 2003).

(a)

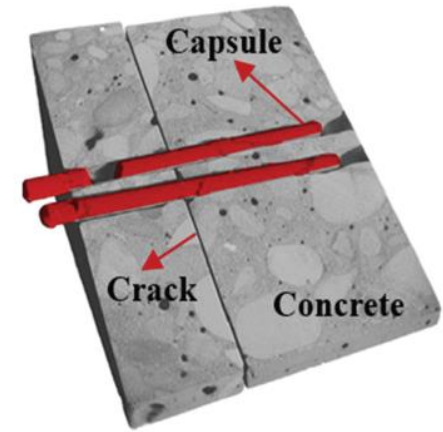

(b)



(c)



Figure 2. Arrangement of self-repairing based on microcapsules concrete: (a) capsule fracture due to crack formation; (b) spread repairing factor in crack; (c) curing by repairing factor (Li, et al., 2013).

The composition of repairing factors (Jackson, et al., 2011), (Haase, et al., 2012), (Haiyan, et al., 2012), (Moll, et al., 2013), (Fischer, et al., 2016), accelerators (Van, et al., 2011), (Feiteira, et al., 2016), capsule content (Pye and Beaudoin, 1992), (Li, et al., 1998), (Zhou, et al., 2006), (Thao, et al., 2011) (Van, et al, 2011), reaction conditions (Yuan, et al., 2013), (Jin, et al., 2014), and fracture patterns (Van, et al., 2011), (Van, et al., 2012), (Van, 2et l., 2013), (Van, et al., 2015) are all elements that impact the curing process of self-repairing based on microcapsules concrete. Furthermore, the experimental procedures used to measure self-repairing effectiveness have an impact on the results (Van, et al., 2011), (Bekas, et al., 2016), (Van, et al., 2016), (Feiteira, et al., 2016). The purpose of this review is to go through several aspects that affect the effectiveness of self-repairing based on microcapsules concrete.

\section{Microcapsules-Based Self-Repairing Factors}

Most of the repairing factors, in self-repairing which based on microcapsules concrete, are polymer materials (Dry, et al., 2003), (Joseph, et al., 2010), (Van, et al., 2011), (Feiteira, et al., 2016), (Van, et al., 2016), which have the potential capacity for crack repairing, like quick polymerisation (White, et al., 2001), stress transfer capability (Dry, et al., 2003), and low viscosity (Feiteira, et al., 2016). The repairing effectiveness of microcapsules-based self-repairing technologies is closely connected to the behavior and reaction mechanism of repairing factors (Huang, et al. 2014). As a result, the development of a perfect repairing factor takes precedence in investigations on microcapsules-based self-repairing concrete. Table 1 summarizes the repairing factors used by microcapsules-based self-repairing concrete, which are classified into two categories: single component repairing factors and multicomponent repairing factors. Premature chemical interactions among the accelerators and repairing factors before they flow into fractures may be the major constraint for engineering applications using multicomponent repairing factors (Van, et al., 2011), (Gardner, et al., 2014). 
Table 1. repairing factors used by microcapsules-based self-repairing concrete.

\begin{tabular}{|c|c|c|c|c|c|c|c|}
\hline 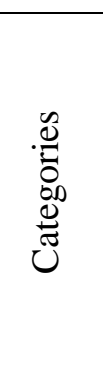 & 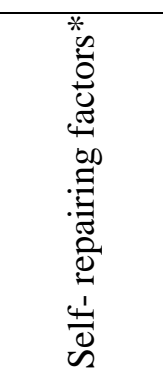 & 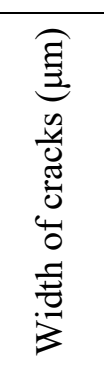 &  & 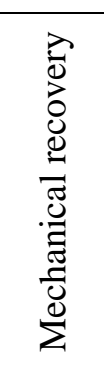 & 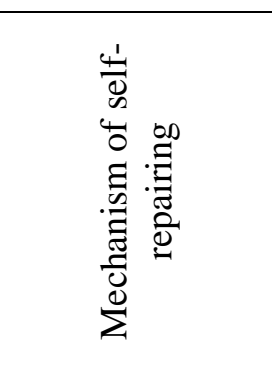 & 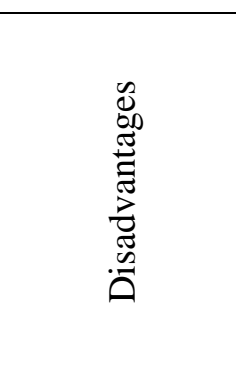 & $\frac{4}{\mathscr{\nu}}$ \\
\hline  & PU & $\begin{array}{c}225- \\
300\end{array}$ & - & $\begin{array}{l}35- \\
80 \%\end{array}$ & $\begin{array}{l}\text { In a wet } \\
\text { environment, } \\
\text { polymerization } \\
\text { is increased. }\end{array}$ & $\begin{array}{l}\text { Premature } \\
\text { reaction }\end{array}$ & $\begin{array}{c}\text { (Van, et al. 2011), } \\
\text { (Feiteira, et al., } \\
\text { 2016), } \\
\text { (Van, et al., 2012), } \\
\text { (Maes, et al, 2014), } \\
\text { (Feiteira, et al., } \\
\text { 2017), } \\
\text { (Minnebo, et al., } \\
\text { 2017). }\end{array}$ \\
\hline  & PU & 250 & - & $\begin{array}{l}35- \\
80 \%\end{array}$ & $\begin{array}{l}\text { Polymerization } \\
\text { in wet } \\
\text { environment. }\end{array}$ & $\begin{array}{l}\text { Detachment } \\
\text { from the } \\
\text { fracture face; } \\
\text { load- } \\
\text { concentration } \\
\text { at the inter- } \\
\text { face. }\end{array}$ & $\begin{array}{c}\text { (Van, et al., 2016), } \\
\text { (Van, et al., 2013), } \\
\text { (Dunhill, 2016), } \\
\text { (Van den, et al., } \\
\text { 2016). }\end{array}$ \\
\hline 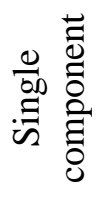 & ER & 300 & $\begin{array}{c}100 \\
\text { minutes }\end{array}$ & $30 \%$ & $\begin{array}{l}\text { Harden when } \\
\text { pressured or } \\
\text { heated. }\end{array}$ & $\begin{array}{l}\text { Long } \\
\text { duration } \\
\text { curing; high } \\
\text { viscosity }\end{array}$ & $\begin{array}{c}\text { (Nishiwaki, et al., } \\
\text { 2006), } \\
\text { (Thao, et al., 2009). }\end{array}$ \\
\hline 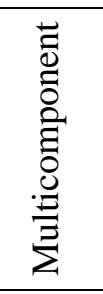 & ER & $\begin{array}{c}225- \\
300\end{array}$ & 24 hours & $\begin{array}{l}35- \\
80 \%\end{array}$ & $\begin{array}{l}\text { Rapid hardening } \\
\text { with reduced } \\
\text { viscosity. }\end{array}$ & $\begin{array}{l}\text { harden and } \\
\text { insufficient } \\
\text { mixing. }\end{array}$ & $\begin{array}{c}\text { (Nishiwaki, et al., } \\
\text { 2006), } \\
\text { (Haiyan, et al., } \\
\text { 2012), } \\
\text { (Van, et al., 2012), } \\
\text { (Yuan, et al., 2013), } \\
\text { (Li, et al., 2013). } \\
\end{array}$ \\
\hline  & $\mathrm{CA}$ & $<100$ & seconds & - & $\begin{array}{l}\text { After tracing } \\
\text { hydroxide ions, } \\
\text { fast anionic } \\
\text { polymerization } \\
\text { occurs. }\end{array}$ & $\begin{array}{l}\text { Demand for } \\
\text { oxygen and } \\
\text { water; } \\
\text { repaired } \\
\text { cracks were } \\
\text { restricted to } \\
100 \mu \mathrm{m} .\end{array}$ & $\begin{array}{c}\text { (Li, et al., 1998), } \\
\text { (Joseph, et al., } \\
\text { 2010), } \\
\text { (Gardner, et al., } \\
\text { 2014). }\end{array}$ \\
\hline 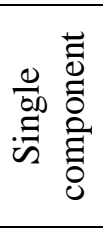 & $\mathrm{Na}_{2} \mathrm{SiO}_{3}$ & 40 & - & $\begin{array}{l}20- \\
26 \%\end{array}$ & $\begin{array}{l}\text { C-S-H gels are } \\
\text { made by } \\
\text { reacting } \\
\mathrm{Ca}(\mathrm{OH})_{2} \text { with } \\
\mathrm{Na}_{2} \mathrm{SiO}_{3} .\end{array}$ & $\begin{array}{l}\text { Mechanical } \\
\text { recuperation } \\
\text { ability is } \\
\text { limited. }\end{array}$ & $\begin{array}{c}\text { (Mostavi, et al., } \\
\text { 2015) }\end{array}$ \\
\hline
\end{tabular}




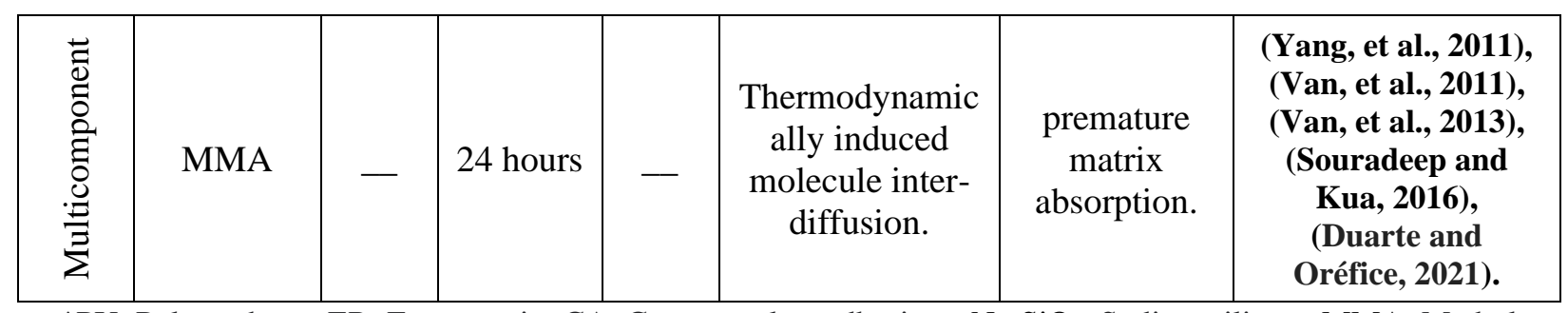

*PU: Polyurethane; ER: Epoxy resin; CA: Cyanoacrylate adhesives; $\mathrm{Na}_{2} \mathrm{SiO}_{3}$ : Sodium silicate; MMA: Methyl methacrylate

\subsection{Polyurethane repairing factor:}

The crack-repairing process is aided by a polyurethane-based repairing factor that foams and expands when a chemical reaction occurs. Because the expansion may seal bigger cracks, a small amount of repairing factor is sufficient for massive crack repairing (Van, et al., 2011). Van \& coworkers (Van, et al., 2016) demonstrated that the polymerization reaction required just a little amount of moisture in the cementitious materials, making polyurethane a versatile repairing factor. They also discovered that more than fifty percent of the original resistance and stiffness may be restored, and the water permeability is significantly reduced following polyurethane self-repairing (Van, et al., 2011), as evidenced by neutron radiography visualization data (Zhang, et al., 2014). For initial fractures with widths of one hundred and three hundred microns, Maes \& co-workers (Maes, et al., 2014) discovered that polyurethane can minimize chloride penetration along the crack route by seventy-six and thirty-three percent, respectively. Many investigations (Maes , et al., 2014), (Van, et al., 2015), have confirmed the self-repairing efficacy and benefits of the polyurethane repairing factor. As a result, current studies on polyurethane-based repairing factors focus on establishing the particular characteristics needed to achieve great repairing results, such as the accelerator, appropriate viscosity, stiffness, Young's modulus, interface qualities, strain capacity, and bonding strength. Feiteira \& co-workers (Feiteira, et al., 2016) investigated the strain-capacity of cured polyurethane-based polymers under repeated load (ACI 224R, 2001), (BS, 2013), taking into account elongation deformation of fatigue-cracks. They discovered that a polyurethane-based repairing factor with an extremely-low viscosity (two hundred millipascals second) may fulfill strain capacity requirements of fifty to hundred percent and decrease failures caused by foam structure breakup, and these results have been approved by Feiteira $\&$ co-workers (Feiteira, et al., 2017). Furthermore, they claimed that flexible polymer materials with Young's modulus less than $10 \mathrm{MPa}$ may resist cracks spread, arrest new cracks from forming, and minimize interface stress, reducing bonding detachment. Dry et co-workers (Dry, et al., 2003), on the other hand, discovered that the modulus of elasticity of adhesives-repairing factor may impact its capacity to repair. They reported that low stiffness might lead to low recovered stiffness values, while a stiff adhesive can simply transmit stress through cracks, enabling the cracks to continue to grow. However, Gilabert et al. (Gilabert, et al., 2017) used tensile testing to assess the resistance contribution of a cured polyurethane-based repairing factor, and postulated a linear relation between the crack-opening size (COS) and the ultimate tensile strength. The ultimate stress varied from 3.7 MPa for a COS of 50.8 micrometers to $1.2 \mathrm{MPa}$ for a COS of 381 micrometers. Despite the fact that several investigations were done to enhance the self-repairing effectiveness of 
polyurethane repairing factors, there is still no consensus on particular self-repairing efficiency assessment criteria. More controversially, four point flexural results for the microencapsulated polyurethane-based repairing factor, in large-scale concrete beams, are even varied due to exposed crack interfaces and insufficient amount of repairing factor (Karaiskos, et al., 2016). Figure 3 depicts the polyurethane-based repairing factor's capacity to recover mechanical characteristics. Basically, within the first or second stages of reloading, the variance in restored mechanical resistance is significantly smaller than that of regained stiffness. The effectiveness of regained stiffness has been investigated by Minnebo (Minnebo, et al., 2017). They reported a 104 percent through the second reloading, and this result was greater than Van et al.'s result (Van, et al., 2011) by 50 percent.

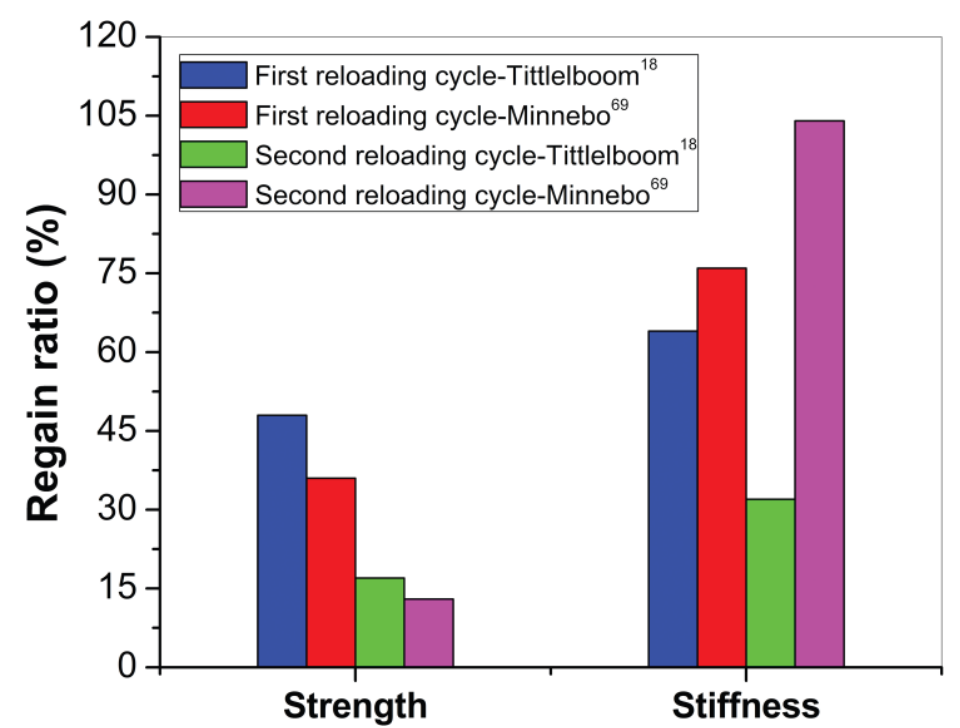

Figure 3. comparative on self-repairing effectiveness of polyurethane repairing factors (Van, et al., 2012), (Minnebo, et al., 2017).

\subsection{Epoxy resin repairing factor}

Epoxy resin (ER), which may be hardened by pressurization or heating, is another early repairing factor (Blaiszik, et al., 2009). Thao \& co-workers (Thao, et al., 2009) used glass tubes to embed ER in a steel-mesh-reinforced mortar sample, resulting in a thirty percent increase in resistance relative to the initial resistance following repeated autonomic repairing. Despite the high selfrepairing outcome provided by the rapid hardening reaction of ER in a sophisticated heating selfrepairing system for concrete described by Nishiwaki (Nishiwaki, et al., 2006), the curing process required approximately 100 minutes due to the high viscosity of this type of repairing factor. As a result, current studies into ER repairing factors have focused on decreasing the duration of curing by including accelerators, which known as multiple-components ER repairing factor. Li (Li, et al., 2013) used polyether-amine as a hardener of repairing factors to improve repairing efficiency in polymer. Moreover, other studies found that diluting this type of ER improved the repairing process. Van (Van, et al., 2011) combined epoxy with methyl-methacrylate to create a repairing 
factor with reduced viscosity and observed a significant increase in water permeability. They also used two-component repairing factors made from polyurethane and ER from two different tubes to speed up the polymerizing procedure. Thao (Thao, et al., 2011) showed that an epoxy-polymer with low viscosity (two hundred and fifty to five hundred millipascal second) may flow easily through cracks and repair quickly, but the precise viscosity still has to be studied further.

\subsection{Cyanoacrylate Repairing Factor}

The self-repairing chemical cyanoacrylate, which is found in hollow glass fibers, was first employed as superglue to patch cracks in cementitious materials. According to Li (Li, et al., 1998), the elastic-modulus recovery of SHCC reinforced beams under cyclic loading was used to assess the self-repairing efficiency of cyanoacrylate, however the thickness of repaired cracks was restricted to fifty micrometers. Although the low viscosity of the repairing factor aided the quick curing process (in seconds) when moisture and oxygen were present, the fracture repairing ability was limited to less than a hundred micrometers because of the capillary needed (Gardner, et al., 2014). Short setting times, might result in inadequate permeation of the repairing factor in the cracks, resulting in un-reacted cyanoacrylate in the capsule. Moreover, Lark (Joseph, et al., 2010) showed that the remaining cyanoacrylate may stay liquid for up to seven days, possibly indicating a tertiary repairing effect, which Gardner (Gardner, et al., 2014) verified. The high bonding strength among cured cyanoacrylate and the fracture surfaces, compared to other repairing factors, can inhibit new crack development during reloading, and the process of curing could be expedited via the alkaline environment conditions (Li, et al., 1998), (Joseph, et al., 2010), (Gardner, et al., 2014).

\section{4 $\mathrm{Na}_{2} \mathrm{SiO}_{3}$ Solution Repairing Factor}

When $\mathrm{Na}_{2} \mathrm{SiO}_{3}$ solution interacts with $\mathrm{Ca}(\mathrm{OH})_{2}$ in cementitious materials, calcium-silicate hydrate (CSH) gels are formed to repairing cracks. Gilford \& co-worker (Gilford, et al., 2014) observed an enhancement of eleven percent in Young's modulus of concrete after being repaired by $\mathrm{Na}_{2} \mathrm{SiO}_{3}$ packed with microcapsules. However, Mostavi (Mostavi, et al., 2015) created a double-shelled microcapsules contained $\mathrm{Na}_{2} \mathrm{SiO}_{3}$, and focused on the capsules' performance. Because the concentration of $\mathrm{Na}_{2} \mathrm{SiO}_{3}$ solution affects self-repairing efficiency, the exhaustion of repairing factors and poor mechanical resistance may limit the engineering use of $\mathrm{Na}_{2} \mathrm{SiO}_{3}$ solution ( $\mathbf{L i}$ and Hou 2005), (Leung, et al., 2011).

\subsection{Methyl methacrylate Repairing Factor}

Few researches have used methyl methacrylate as a repairing factor. Diry (Diry, 2000) observed the effective spread of methyl methacrylate from fibers into cement, after exposed to heat, and achieved favorable concrete permeability results. Yang \& co-workers (Yang, et al., 2011) developed a novel form of self-repairing material by microencapsulating methyl methacrylate in a silica gel shell and observed an enhancement in the gas permeability test. Van (Van, et al., 2013), on the other hand, filled the methyl methacrylate in borosilicate capillary glass-tubes and found no 
enhancement in the water ingress test when compared to the untreated fractures. The cause for this might be due to the repairing ingredient in the capsules curing too quickly.

\section{ASSESSMENT OF SELF-REPAIRING EFFICIENCY}

\subsection{Restoring of durability}

The basic objective of self-repairing concrete is to promote durability recovery, which defines the indication for self-repairing efficiency evaluation. When evaluating the durability of concrete infrastructure, fluid permeability is a direct indicator of concrete's service life (Li, et al., 2013), (Huang, et al., 2016), (Milla, et al., 2021). As a result, the most often used method for determining the durability of self-repairing concrete is the permeability test. The setup and technique for the permeability test were described in detail by Van \& co-workers (Van, et al., 2011). The coefficient of permeability is computed quantitatively utilizing Darcy's law by measuring the drop in water column with time, as shown in Figure 4a. This method has been used extensively to assess the repairing effectiveness of single pre-oriented cracks, demonstrating that the microencapsulation procedure is extremely successful in restoring durability. Van \& co-workers (Van, et al., 2011) examined water permeability reductions in concrete with cured fractures, and the findings ranged from one hundred and to ten thousand for concrete beams containing various capsules. Nevertheless, in the large-scale lab test with many fractures shown in Figure $4 \mathrm{~b}$, evaluating the repairing effectiveness and measuring the permeability of each fracture is challenging (Van, et al., 2015), (Van, et al., 2016). The capillary absorptivity appears to be more reliable than the permeability test in determining the durability of crack-repairing concrete in unsaturated condition (Van, et al., 2013), (Van den, et al., 2016), (Van Belleghem, et al., 2016). gravimetric analysis has been widely used in the past to easily compute the quantitative capillary absorption value, but it is unable to depict the spatial distributions of water (Feiteira, et al., 2016). To acquire characteristics of water distribution inside discrete fractures, X-ray computed scanning and neutron radiographic methods were used. Van (Van, et al., 2013) initially used neutron radiographic to observe the moisture absorption of various samples as well as the water distribution on repaired fracture surfaces, and they looked at the influence of viscosity on self-repairing ability (Van den, et al., 2016). Although the accuracy of neutron radiographic are excellent, the test's expensive cost prevents it from becoming more widely used. As a result, using a low-cost X-ray radiographic approach to test the durability of crack-repairing concrete may be cost-effective (Van Belleghem, et al., 2016). Few investigations have looked into chloride diffusion of microcapsulesbased self-repairing concrete in regards to permeability or capillary absorption of water. Maes (Maes, et al., 2014) used an acid-soluble chloride -extraction test to investigate self-repairing capability and discovered that microencapsulated polyurethane can inhibit chloride spreading from cracks with widths ranging from one hundred to three hundred micrometers. Nevertheless, because of the weaker capillary strength among fracture surfaces than in capsules, inadequate repairing response generates significant chloride permeation in big cracks (Joseph, et al., 2010). Furthermore, Yang \& co-workers (Yang, et al., 2011) focused on the permeability of gas and 
discovered that oil-core/silica-gel shell micro-capsules reduced the permeability of gas by roughly 50.2 percent for self-repairing cement paste.



(b)

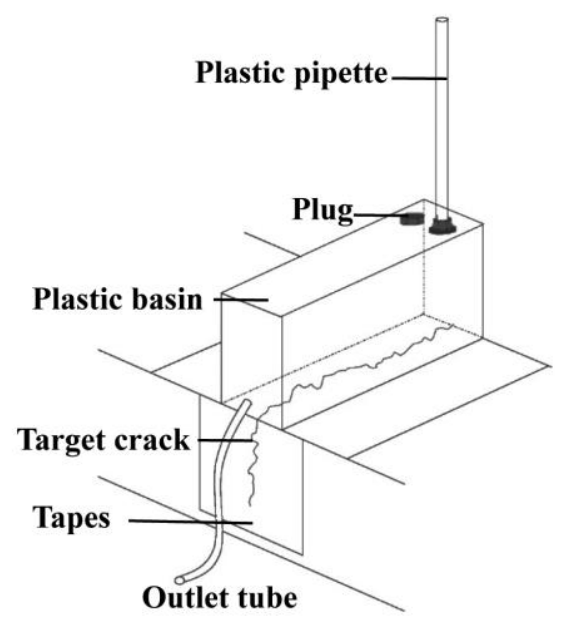

Figure 4. Restored mechanical characteristics of self-repairing concrete with various cyclic reloading: (a) single fracture; (b) multiple fracture (Dry, 1996).

\subsection{Mechanical Characteristics Restoring}

When the self-repairing action begins and the repairing factor has fully hardened, the self-repairing concrete is reloaded and tested for resistance, toughness, and stiffness using three or four-point flexural methods that rely on stress-strain ratios or load-displacement relations. Van \& co-workers (Van, et al., 2011) compared the mechanical loading relations of untreated, conventionally cured, and autonomously repairing techniques to determine the self-repairing effectiveness of microcapsules-based self-repairing concrete. In Figure 5, the ultimate-strength and slope of the load-displacement ratio relate to strength and stiffness indicators, correspondingly, demonstrating the recovering effectiveness of mechanical characteristics for autonomous repairing concrete. 


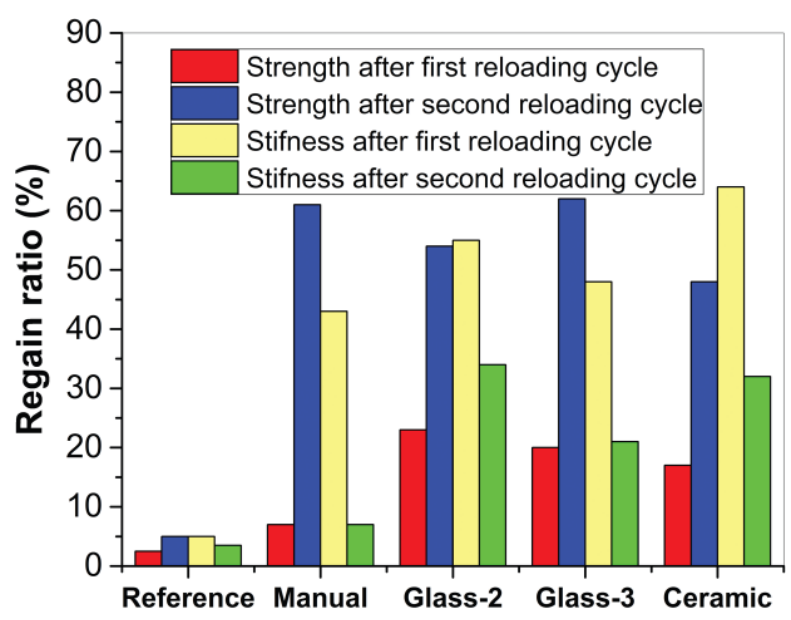

Figure 5. mechanical characteristics for self-repairing concrete (Dry, 1996), (Van, et al., 2015).

Feiteira \& co-workers (Feiteira, et al., 2016) used a 3-point flexural test to investigate the loaddisplacement relationship of fracturing and fracture spreading cycles in repairing and nonrepairing samples containing micro-capsulated polymer precursors. They only got a thirty percent mechanical stiffness recovering for each thirty days with thicknesses approximately twenty micrometers due to the poor stiffness of the polymers utilized. Likewise, Thao \& co- workers (Thao, et al., 2009) discovered a thirty percent grow in resistance with repeated cyclic loads compared to the initial resistance. For another mechanical studies (Van, et al., 2012), the microcapsules-based self-repairing approach restored almost eighty percent of the actual resistance and stiffness. The recovering capability of mechanical resistance might also be greatly impacted by fracture modes, even with the identical repairing factors and capsules. For instance, in the case of self-repairing concrete with many cracks, the 4-point flexural test fails to produce satisfactory results in terms of mechanical resistance recovering capability (Van, et al., 2016). Dunhill (Dunhill, 2016) also found some surprising mechanical recovery findings for a concrete beam exposed to a 4-point flexural force.

\subsection{Conception of Self-Repairing Action}

High resolution x-ray computed tomography (HRXCT), digital image correlation (DIC), fluorescence microscope, and photomicrograph are prevalent techniques gives magnified conception for the behavior and action of self-repairing concrete like width of fracture, place of micro-encapsules, and spreading of repairing-factor. Van \& co-workers (Van, et al., 2016) used all of the mentioned-above methodologies to analyze and assess the self-repairing activity of polyurethane repairing factors. Figure 6 shows a summary of the various outcomes. Digital image correlation technique is most commonly used to examine fracture modes in the surfaces of concrete samples (Xiao, et al., 2012), (Li, et al., 2012), (Zhu, et al., 2020), (Ahn, et al., 2021). According to the digital image correlation data in Figure $6 \mathrm{a}$, a greater fracture mode appeared in the concrete beam's center section. Feiteira \& co-workers (Feiteira, et al., 2017) employed digital image correlation to track the fracture opening over the whole length of the fracture, and they found a 
rather serious fracture widening-process when stiff polymers were used as the repairing factor. To analyze the position and state of capsules, X-ray scanning was used to get 3-dimensional imaging of the inside component of concrete. The micro-capsules were roughly thirteen millimeters under the upper surface of the sample, as seen in Figure 6b. Because of the inadequate capillarity load, the micro-capsules are not entirely emptied, and the repairing factor within the fracture distributes unevenly. Gilabert \& co-workers (Gilabert, et al., 2017) validated the same finding utilizing micro computed tomography analysis. Van \& co-workers (Van, et al., 2015) found that if a fracture propagates because the presence of capsule, is reliant on chance, except when the cement paste operates as weak areas between the capsule and the mixture and promote the fracture formation, dependent on X-ray radiography of concrete beam samples with actual cracks. Electron microscopic visualization methods are commonly used to quantify the fracture size and observe the repairing factor distribution, as illustrated in Figure 6c. According to the results, the beam with micro-capsulated polyurethane has the best percentage of fracture sealing and the greatest ability to repair bigger fractures with a width of one hundred and ninety-eight micrometers.
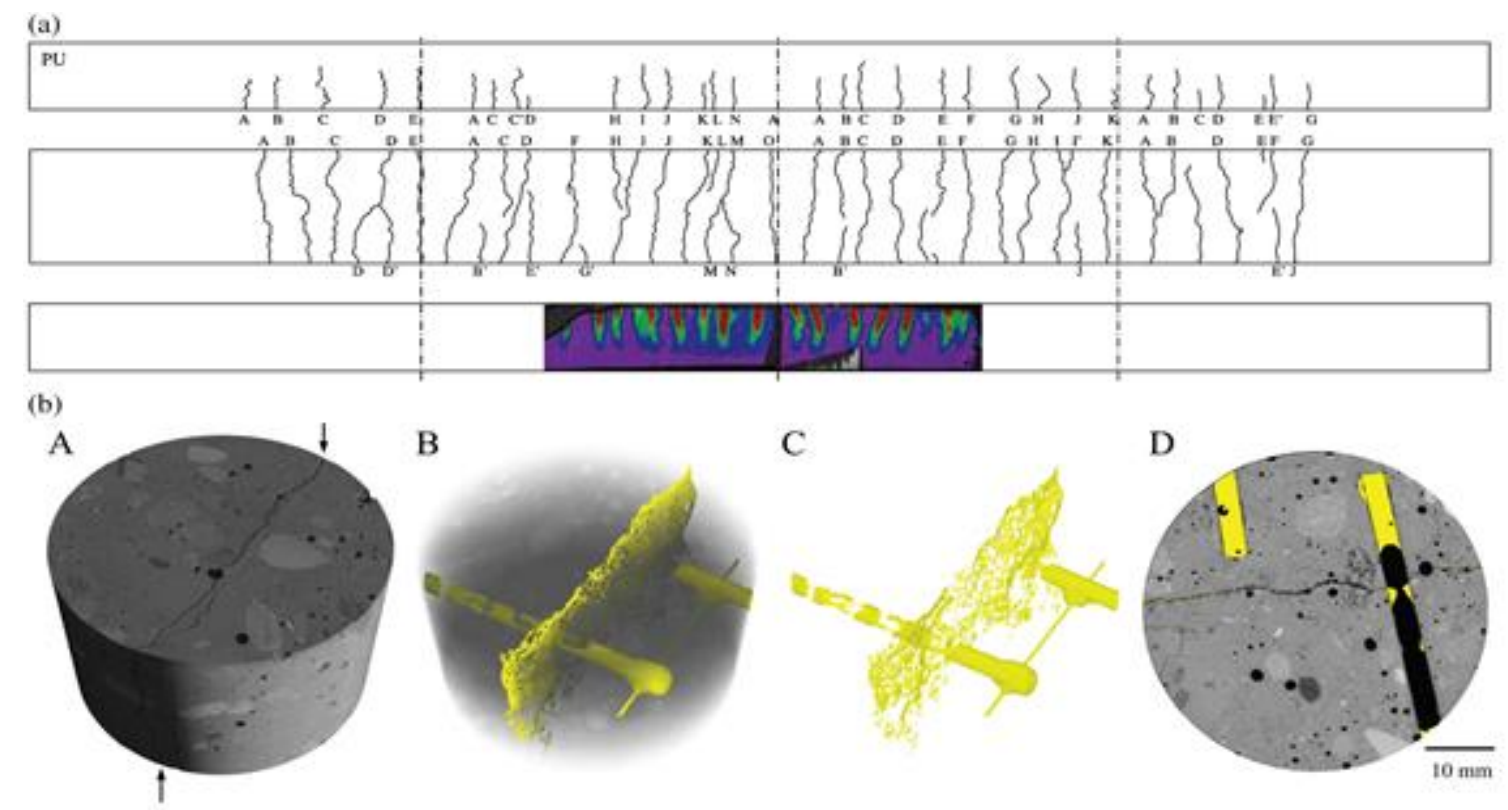
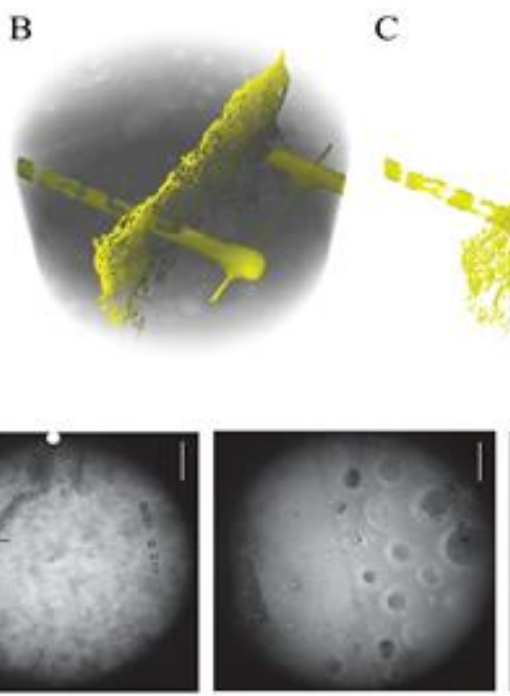

IV F $\mid 32 \mu \mathrm{m}$

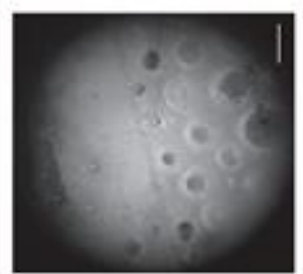

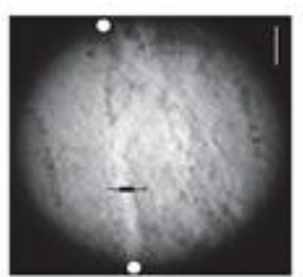

III I | $189 \mu \mathrm{m}$
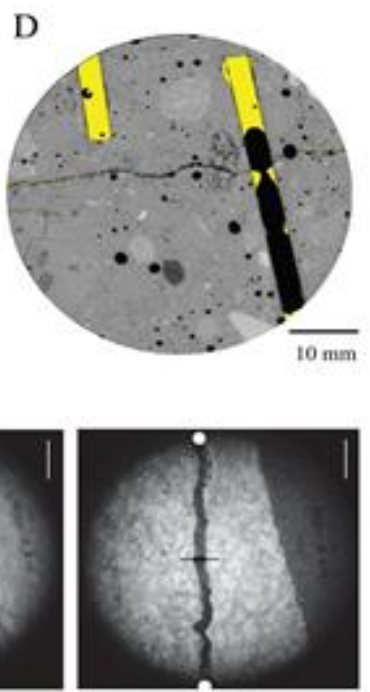

IV A $\mid 168 \mu \mathrm{m}$

Figure 6. Conception of self-repairing fractures in concrete by various techniques: (a) DIC; (b) X-ray scanning; (c) electron microscopic visualization (Van, et al., 2015). 


\section{CONCLUSION:}

Microcapsules-based self-repairing method has shown to be a successful way for concrete fracture repair. Microcapsules-based self-repairing method relies heavily on repairing factors and encapsulation processes. Several experimental investigations have been conducted to assess the efficacy of the self-repairing approach. The following are the associated conclusions and recommendations:

- Polyurethane polymer is the most effective of all existing self-repairing factors, with excellent flexibility, a comparably quick curing duration, and a self-repairing mechanism that does not require water. Applied stress near the interface, separation of hardened selfrepairing factor, insufficient blending, and early response all require additional adjustments.

- It's hard to identify the most accurate and trustworthy effectiveness analytical approach for self-repairing performance since there aren't any standardized self-repairing effectiveness characteristics or assessment methods. Mechanical testing and permeability measurements are commonly used to evaluate the effectiveness of microcapsules-based self-repairing concrete. Methods including digital image correlation, High resolution x-ray computed tomography (X-ray CT), and neutron tomography, might help researchers understand better self-repairing processes.

More studies are needed in terms of determining the appropriate viscosity, elastic module fit, strain capacity, and binding force of polyurethane polymers repairing factors. Aside from capsules content and repairing factors, more investigation into the fracture growth behavior of self-repairing which is based on micro-capsules for cement pozzolana binding materials, the kinetics of repairing factors in discrete fracture surfaces, and other thorough aspects is needed.

\section{REFERNCES}

- ACI, 2001. ACI 224R-01: Control of cracking in concrete structures.

- Ahn, E., Kim, H., Gwon, S., Oh, S.R., Kim, C.G., Sim, S.H. and Shin, M., 2021. Monitoring of self-healing in concrete with micro-capsules using a combination of aircoupled surface wave and computer-vision techniques. Structural Health Monitoring, p.14759217211041002.

- Bekas, D.G., Tsirka, K., Baltzis, D. and Paipetis, A.S., 2016. Self-healing materials: A review of advances in materials, evaluation, characterization and monitoring techniques. Composites Part B: Engineering, 87, pp.92-119.

- Blaiszik, B.J., Caruso, M.M., McIlroy, D.A., Moore, J.S., White, S.R. and Sottos, N.R., 2009. Microcapsules filled with reactive solutions for self-healing materials. Polymer, 50(4), pp.990-997.

- British Standards Institution, 2013. Products and Systems for the Protection and Repair of Concrete Structures-Definitions, Requirements, Quality Control and Evaluation of Conformity.

- Cowie, J. and Glasser, F.P., 1992. The reaction between cement and natural waters containing dissolved carbon dioxide. Advances in Cement Research, 4(15), pp.119-134. 
- Cuenca, E. and Ferrara, L., 2017. Self-healing capacity of fiber reinforced cementitious composites. State of the art and perspectives. KSCE Journal of Civil Engineering, 21(7), pp.2777-2789.

- De Belie, N., Gruyaert, E., Al-Tabbaa, A., Antonaci, P., Baera, C., Bajare, D., Darquennes, A., Davies, R., Ferrara, L., Jefferson, T. and Litina, C., 2018. A review of self-healing concrete for damage management of structures. Advanced materials interfaces, 5(17), p.1800074.

- Diry, C.M., 2000. Three designs for the internal release of sealants, adhesives, and waterproofing chemicals into concrete to reduce permeability. Cement and Concrete Research, 30(12), pp.1969-1977.

- Dry, C., 1994. Matrix cracking repair and filling using active and passive modes for smart timed release of chemicals from fibers into cement matrices. Smart Materials and Structures, 3(2), p.118.

- Dry, C., 1996. Procedures developed for self-repair of polymer matrix composite materials. Composite structures, 35(3), pp.263-269.

- Dry, C., Corsaw, M. and Bayer, E., 2003. A comparison of internal self-repair with resin injection in repair of concrete. Journal of adhesion science and technology, 17(1), pp.7989.

- Duarte, É.C. and Oréfice, R.L., 2021. Self-healing interfaces of poly (methyl methacrylate) reinforced with carbon fibers decorated with carbon quantum dots. Journal of Applied Polymer Science, 138(1), p.49644.

- Dunhill, T., 2016. 19th World Conference on Non-Destructive Testing a huge success. Insight, 58(10).

- Feiteira, J., Gruyaert, E. and De Belie, N., 2016. Self-healing of moving cracks in concrete by means of encapsulated polymer precursors. Construction and Building Materials, 102, pp.671-678.

- Feiteira, J., Tsangouri, E., Gruyaert, E., Lors, C., Louis, G. and De Belie, N., 2017. Monitoring crack movement in polymer-based self-healing concrete through digital image correlation, acoustic emission analysis and SEM in-situ loading. Materials \& Design, 115, pp.238-246.

- Ferrara, L., Krelani, V. and Carsana, M., 2014. A “fracture testing” based approach to assess crack healing of concrete with and without crystalline admixtures. Construction and Building Materials, 68, pp.535-551.

- Ferrara, L., Krelani, V. and Moretti, F., 2016. On the use of crystalline admixtures in cement based construction materials: from porosity reducers to promoters of self healing. Smart materials and structures, 25(8), p.084002.

- Fischer, H.R. and García, S.J., 2016. Active protective coatings: Sense and heal concepts for organic coatings. In Active Protective Coatings (pp. 139-156). Springer, Dordrecht.

- Gardner, D., Jefferson, A., Hoffman, A. and Lark, R., 2014. Simulation of the capillary flow of an autonomic healing agent in discrete cracks in cementitious materials. Cement and Concrete Research, 58, pp.35-44.

- Gilabert, F.A., Garoz, D. and Van Paepegem, W., 2015. Stress concentrations and bonding strength in encapsulation-based self-healing materials. Materials \& Design, 67, pp.28-41.

- Gilabert, F.A., Van Tittelboom, K., Tsangouri, E., Van Hemelrijck, D., De Belie, N. and Van Paepegem, W., 2017. Determination of strength and debonding energy of a glass- 
concrete interface for encapsulation-based self-healing concrete. Cement and concrete composites, 79, pp.76-93.

- Gilabert, F.A., Van Tittelboom, K., Van Stappen, J., Cnudde, V., De Belie, N. and Van Paepegem, W., 2017. Integral procedure to assess crack filling and mechanical contribution of polymer-based healing agent in encapsulation-based self-healing concrete. Cement and Concrete Composites, 77, pp.68-80.

- Gilford III, J., Hassan, M.M., Rupnow, T., Barbato, M., Okeil, A. and Asadi, S., 2014. Dicyclopentadiene and sodium silicate microencapsulation for self-healing of concrete. Journal of Materials in Civil Engineering, 26(5), pp.886-896.

- Haase, M.F., Grigoriev, D.O., Möhwald, H. and Shchukin, D.G., 2012. Development of nanoparticle stabilized polymer nanocontainers with high content of the encapsulated active agent and their application in water-borne anticorrosive coatings. Advanced Materials, 24(18), pp.2429-2435.

- Haiyan, L., Rongguo, W. and Wenbo, L., 2012. Preparation and self-healing performance of epoxy composites with microcapsules and tungsten (VI) chloride catalyst. Journal of reinforced plastics and composites, 31(13), pp.924-932.

- Huang, H., Ye, G. and Damidot, D., 2013. Characterization and quantification of selfhealing behaviors of microcracks due to further hydration in cement paste. Cement and Concrete Research, 52, pp.71-81.

- Huang, H., Ye, G. and Damidot, D., 2014. Effect of blast furnace slag on self-healing of microcracks in cementitious materials. Cement and concrete research, 60, pp.68-82.

- Huang, H., Ye, G. and Pel, L., 2016. New insights into autogenous self-healing in cement paste based on nuclear magnetic resonance (NMR) tests. Materials and Structures, 49(7), pp.2509-2524.

- Huang, H., Ye, G. and Shui, Z., 2014. Feasibility of self-healing in cementitious materials-By using capsules or a vascular system?. Construction and Building materials, 63, pp.108-118.

- Isaacs, B., Lark, R., Jefferson, T., Davies, R. and Dunn, S., 2013. Crack healing of cementitious materials using shrinkable polymer tendons. Structural Concrete, 14(2), pp.138-147.

- Jackson, A.C., Bartelt, J.A. and Braun, P.V., 2011. Transparent Self-Healing Polymers Based on Encapsulated Plasticizers in a Thermoplastic Matrix. Advanced Functional Materials, 21(24), pp.4705-4711.

- Jacobsen, S. and Sellevold, E.J., 1996. Self healing of high strength concrete after deterioration by freeze/thaw. Cement and Concrete Research, 26(1), pp.55-62.

- Jin, H., Mangun, C.L., Griffin, A.S., Moore, J.S., Sottos, N.R. and White, S.R., 2014. Thermally stable autonomic healing in epoxy using a dual-microcapsule system. Advanced materials, 26(2), pp.282-287.

- Joseph, C., Jefferson, A.D., Isaacs, B., Lark, R. and Gardner, D., 2010. Experimental investigation of adhesive-based self-healing of cementitious materials. Magazine of Concrete Research, 62(11), pp.831-843.

- Karaiskos, G., Tsangouri, E., Aggelis, D.G., Van Tittelboom, K., De Belie, N. and Van Hemelrijck, D., 2016. Performance monitoring of large-scale autonomously healed concrete beams under four-point bending through multiple non-destructive testing methods. Smart Materials and Structures, 25(5), p.055003. 


\section{Number 2 Volume 28 February 2022 Journal of Engineering}

- Kessler, M.R., Sottos, N.R. and White, S.R., 2003. Self-healing structural composite materials. Composites Part A: applied science and manufacturing, 34(8), pp.743-753.

- Khaliq, W. and Ehsan, M.B., 2016. Crack healing in concrete using various bio influenced self-healing techniques. Construction and Building Materials, 102, pp.349357.

- $\quad$ Leung, C., Wan, K.T., Shah, S.P., Kim, J.H., Kawashima, S., Andrade, C., Tavares, F., Prieto, M., Tanner, P., Izquierdo, D. and Jensen, O.M., 2011. International RILEM Conference on Advances in Construction Materials through Science and Engineering.

- Li, Q., Kim, N.H., Hui, D. and Lee, J.H., 2013. Effects of dual component microcapsules of resin and curing agent on the self-healing efficiency of epoxy. Composites Part B: Engineering, 55, pp.79-85.

- Li, V.C., Lim, Y.M. and Chan, Y.W., 1998. Feasibility study of a passive smart selfhealing cementitious composite. Composites Part B: Engineering, 29(6), pp.819-827.

- Li, W., Jiang, Z., Yang, Z., Zhao, N. and Yuan, W., 2013. Self-healing efficiency of cementitious materials containing microcapsules filled with healing adhesive: Mechanical restoration and healing process monitored by water absorption. PLoS One, 8(11), p.e81616.

- Li, W., Xiao, J., Sun, Z. and Shah, S.P., 2012. Failure processes of modeled recycled aggregate concrete under uniaxial compression. Cement and Concrete Composites, 34(10), pp.1149-1158.

- $\quad \mathrm{Li}, \mathrm{X}$. and Hou, Z., 2005. Scandium-catalyzed copolymerization of ethylene with dicyclopentadiene and terpolymerization of ethylene, dicyclopentadiene, and styrene. Macromolecules, 38(16), pp.6767-6769.

- Lv, Z. and Chen, H., 2013. Analytical models for determining the dosage of capsules embedded in self-healing materials. Computational Materials Science, 68, pp.81-89.

- Maes, M., Van Tittelboom, K. and De Belie, N., 2014. The efficiency of self-healing cementitious materials by means of encapsulated polyurethane in chloride containing environments. Construction and Building Materials, 71, pp.528-537.

- Mehta, P.K., 1986. Concrete. Structure, properties and materials.

- Milla, J., Cavalline, T.L., Rupnow, T.D., Melugiri-Shankaramurthy, B., Lomboy, G. and Wang, K., 2021. Methods of Test for Concrete Permeability: A Critical Review. Advances in Civil Engineering Materials, 10(1), pp.172-209.

- Minnebo, P., Thierens, G., De Valck, G., Van Tittelboom, K., De Belie, N., Van Hemelrijck, D. and Tsangouri, E., 2017. A novel design of autonomously healed concrete: Towards a vascular healing network. Materials, 10(1), p.49.

- Moll, J.L., Jin, H., Mangun, C.L., White, S.R. and Sottos, N.R., 2013. Self-sealing of mechanical damage in a fully cured structural composite. Composites Science and Technology, 79, pp.15-20.

- Mostavi, E., Asadi, S., Hassan, M.M. and Alansari, M., 2015. Evaluation of self-healing mechanisms in concrete with double-walled sodium silicate microcapsules. Journal of materials in civil engineering, 27(12), p.04015035.

- Muhammad, N.Z., Shafaghat, A., Keyvanfar, A., Majid, M.Z.A., Ghoshal, S.K., Yasouj, S.E.M., Ganiyu, A.A., Kouchaksaraei, M.S., Kamyab, H., Taheri, M.M. and Shirdar, M.R., 2016. Tests and methods of evaluating the self-healing efficiency of concrete: A review. Construction and Building Materials, 112, pp.1123-1132. 
- Nishiwaki, T., Mihashi, H., Jang, B.K. and Miura, K., 2006. Development of self-healing system for concrete with selective heating around crack. Journal of Advanced Concrete Technology, 4(2), pp.267-275.

- Perez, G., Erkizia, E., Gaitero, J.J., Kaltzakorta, I., Jiménez, I. and Guerrero, A., 2015. Synthesis and characterization of epoxy encapsulating silica microcapsules and amine functionalized silica nanoparticles for development of an innovative self-healing concrete. Materials Chemistry and Physics, 165, pp.39-48.

- Pye, G.B. and Beaudoin, J.J., 1992. An energy approach to bond strength determinations in cement systems. Cement and concrete research, 22(4), pp.551-558.

- $\quad$ Roig-Flores, M., Moscato, S., Serna, P. and Ferrara, L., 2015. Self-healing capability of concrete with crystalline admixtures in different environments. Construction and Building Materials, 86, pp.1-11.

- Roig-Flores, M., Pirritano, F., Serna, P. and Ferrara, L., 2016. Effect of crystalline admixtures on the self-healing capability of early-age concrete studied by means of permeability and crack closing tests. Construction and Building Materials, 114, pp.447457.

- Souradeep, G. and Kua, H.W., 2016. Encapsulation technology and techniques in selfhealing concrete. Journal of Materials in Civil Engineering, 28(12), p.04016165.

- Thao, T.D.P., 2011. Quasi-Brittle Self-Healing Materials: Numerical Modelling and Applications in Civil Engineering.

- Thao, T.D.P., Johnson, T.J.S., Tong, Q.S. and Dai, P.S., 2009. Implementation of selfhealing in concrete-Proof of concept. The IES Journal Part A: Civil \& Structural Engineering, 2(2), pp.116-125.

- Van Belleghem, B., Montoya, R., Dewanckele, J., Van den Steen, N., De Graeve, I., Deconinck, J., Cnudde, V., Van Tittelboom, K. and De Belie, N., 2016. Capillary water absorption in cracked and uncracked mortar-A comparison between experimental study and finite element analysis. Construction and Building Materials, 110, pp.154-162.

- Van den Heede, P., Van Belleghem, B., Alderete, N., Van Tittelboom, K. and De Belie, N., 2016. Neutron radiography based visualization and profiling of water uptake in (un) cracked and autonomously healed cementitious materials. Materials, 9(5), p.311.

- Van Tittelboom, K., Adesanya, K., Dubruel, P., Van Puyvelde, P. and De Belie, N., 2011. Methyl methacrylate as a healing agent for self-healing cementitious materials. Smart Materials and structures, 20(12), p.125016.

- Van Tittelboom, K., De Belie, N., Lehmann, F. and Grosse, C.U., 2012. Acoustic emission analysis for the quantification of autonomous crack healing in concrete. Construction and Building Materials, 28(1), pp.333-341.

- Van Tittelboom, K., De Belie, N., Van Loo, D. and Jacobs, P., 2011. Self-healing efficiency of cementitious materials containing tubular capsules filled with healing agent. Cement and Concrete Composites, 33(4), pp.497-505.

- Van Tittelboom, K., Gruyaert, E., De Backer, P., Moerman, W. and De Belie, N., 2015. Self-repair of thermal cracks in concrete sandwich panels. Structural Concrete, 16(2), pp.273-288.

- Van Tittelboom, K., Gruyaert, E., Rahier, H. and De Belie, N., 2012. Influence of mix composition on the extent of autogenous crack healing by continued hydration or calcium carbonate formation. Construction and Building Materials, 37, pp.349-359. 
- Van Tittelboom, K., Snoeck, D., Vontobel, P., Wittmann, F.H. and De Belie, N., 2013. Use of neutron radiography and tomography to visualize the autonomous crack sealing efficiency in cementitious materials. Materials and structures, 46(1), pp.105-121.

- Van Tittelboom, K., Tsangouri, E., Van Hemelrijck, D. and De Belie, N., 2015. The efficiency of self-healing concrete using alternative manufacturing procedures and more realistic crack patterns. Cement and concrete composites, 57, pp.142-152.

- Van Tittelboom, K., Wang, J., Araújo, M., Snoeck, D., Gruyaert, E., Debbaut, B., Derluyn, H., Cnudde, V., Tsangouri, E., Van Hemelrijck, D. and De Belie, N., 2016. Comparison of different approaches for self-healing concrete in a large-scale lab test. Construction and building materials, 107, pp.125-137.

- Vijay, K., Murmu, M. and Deo, S.V., 2017. Bacteria based self healing concrete-A review. Construction and Building Materials, 152, pp.1008-1014.

- White, S.R., Sottos, N.R., Geubelle, P.H., Moore, J.S., Kessler, M.R., Sriram, S.R., Brown, E.N. and Viswanathan, S., 2001. Autonomic healing of polymer composites. Nature, 409(6822), pp.794-797.

- Xiao, J., Li, W., Sun, Z. and Shah, S.P., 2012. Crack Propagation in Recycled Aggregate Concrete under Uniaxial Compressive Loading. ACI Materials Journal, 109(4).

- Yang, Z., Hollar, J., He, X. and Shi, X., 2011. A self-healing cementitious composite using oil core/silica gel shell microcapsules. Cement and Concrete Composites, 33(4), pp.506-512.

- Yldırım, G., Keskin, Ö.K., Keskin, S.B., Şahmaran, M. and Lachemi, M., 2015. A review of intrinsic self-healing capability of engineered cementitious composites: Recovery of transport and mechanical properties. Construction and Building Materials, 101, pp.10-21.

- Yuan, L., Huang, S., Gu, A., Liang, G., Chen, F., Hu, Y. and Nutt, S., 2013. A cyanate ester/microcapsule system with low cure temperature and self-healing capacity. Composites science and technology, 87, pp.111-117.

- Zemskov, S.V., Jonkers, H.M. and Vermolen, F.J., 2011. Two analytical models for the probability characteristics of a crack hitting encapsulated particles: Application to selfhealing materials. Computational materials science, 50(12), pp.3323-3333.

- Zhang, Z., Qian, S. and Ma, H., 2014. Investigating mechanical properties and selfhealing behavior of micro-cracked ECC with different volume of fly ash. Construction and Building Materials, 52, pp.17-23.

- Zhou, J., Huang, M., Sagnang, F. and Soboyejo, W.O., 2006. Interfacial failure of a dental cement composite bonded to glass substrates. Dental Materials, 22(6), pp.585-591.

- Zhu, X., Ye, F., Cai, Y., Birgisson, B. and Yu, Y., 2020. Digital image correlation-based investigation of self-healing properties of ferrite-filled open-graded friction course asphalt mixture. Construction and Building Materials, 234, p.117378. 